\title{
Vitamin D Supplementation in Sarcoidosis: A Double-Edged Sword
}

\author{
Rishikesh Chandran $^{1} \quad$ Lakshmi Nagendra ${ }^{20}$ Shrikrishna Acharya ${ }^{2}$ Giridhar Belur Hosmane ${ }^{3}$ \\ Vijith Shetty ${ }^{4}$ Adithi Kellarai $^{1}$ Bhagavan K.R. ${ }^{5}$ \\ ${ }^{1}$ Department of General Medicine, K.S. Hegde Medical Academy, \\ Mangalore, Karnataka, India \\ 2 Department of Endocrinology, K.S. Hegde Medical Academy, \\ Mangalore, Karnataka, India \\ ${ }^{3}$ Department of Pulmonology, K.S. Hegde Medical Academy, \\ Mangalore, Karnataka, India \\ ${ }^{4}$ Department of Oncology, K.S. Hegde Medical Academy, Mangalore, \\ Karnataka, India \\ ${ }^{5}$ Department of General Surgery, K.S. Hegde Medical Academy, \\ Mangalore, Karnataka, India \\ J Health Allied Sci ${ }^{\mathrm{NU}}$ 2022;12:214-216. \\ Address for correspondence Lakshmi Nagendra, MD, DM, DNB, \\ Department of Endocrinology, K.S. Hegde Medical Academy, \\ Mangalore 575018, Karnataka, India \\ (e-mail: drlakshminagendra@gmail.com).
}

\begin{abstract}
Sarcoidosis is complicated by disordered vitamin D and calcium metabolism, which has important implications on disease activity and bone health. Although the majority of the patients with sarcoidosis are typically deficient in 25 -hydroxyvitamin $D$, repletion of vitamin $D$ is controversial in light of the hypercalcemia risk. Presently, there are no clear guidelines regarding vitamin $D$ supplementation as a part of osteoporosis prevention in

Keywords

- Sarcoidosis

- vitamin D deficiency

- hypercalcemia patients with vitamin D deficiency and sarcoidosis. We report a patient with sarcoidosis who presented with severe hypercalcemia following vitamin D supplementation and review the debated role of vitamin $\mathrm{D}$ supplementation in vitamin D-deficient sarcoid patients.
\end{abstract}

\section{Introduction}

There is an extremely high prevalence of vitamin D deficiency in India, necessitating widespread vitamin D supplementation. ${ }^{1}$ Weekly oral cholecalciferol $(60,000$ units) for 6 to 8 weeks is the most commonly used regimen in India. ${ }^{2}$

Sarcoidosis is a multisystem disease of unknown cause, characterized by the presence of activated T-cells, mononuclear phagocytes, and noncaseating granulomas. ${ }^{3}$ The prevalence of hypercalcemia in patients with sarcoidosis is reported to be approximately 5 to $11 \%$. Activated macrophages in sarcoid granulomas are capable of upregulating extrarenal 1a-hydroxylase which can result in hypercalcemia. Expression of parathyroid hormone-related protein
(PTH-rP) in sarcoid macrophages, exerting an autocrine action of 1a-hydroxylase, has also been reported. Also, increased levels of IFN-g in sarcoidosis is known to stimulate the production of 1,25-dihydroxyvitamin $\mathrm{D}$ by alveolar macrophages. ${ }^{4}$ While hypercalcemia complicating sarcoidosis is well-known, severe hypercalcemia of more than 14 $\mathrm{mg} / \mathrm{dL}$ has been rarely reported. ${ }^{5}$

Although a majority of the patients with sarcoidosis are typically deficient in 25-hydroxyvitamin $\mathrm{D}^{6}$ repletion of vitamin D is controversial in light of the hypercalcemia risk. Presently, there are no clear guidelines regarding vitamin D supplementation as a part of osteoporosis prevention in patients with vitamin $\mathrm{D}$ deficiency and sarcoidosis. We
DOI https://doi.org/ $10.1055 / \mathrm{s}-0041-1736280$ ISSN 2582-4287.




report a patient with sarcoidosis who presented with severe hypercalcemia following vitamin D supplementation and discuss the review of literature regarding role of vitamin D supplementation in vitamin D-deficient sarcoid patients.

\section{Case Report}

A 50-year-old lady presented with a history of generalized weakness, vague abdominal pain, and significant weight loss of about $15 \mathrm{kgs}$ in the preceding 9 months. She also gave a history of on and off fever, night sweats, and dry cough. She was initially hospitalized under the care of a general surgeon with the suspicion of symptomatic cholelithiasis. Documentation of hypercalcemia on a routine evaluation prompted a referral to endocrinology.

General physical examination was non-contributory, and peripheral lymphadenopathy could not be appreciated. Per abdomen examination revealed hepatosplenomegaly. On further probing regarding vitamin D supplementation, the patient gave a history of having received 60,000 IU vitamin D3 once a week for 4 weeks for vitamin D deficiency 3 weeks before presentation to our hospital. Laboratory investigations at this time showed a high erythrocyte sedimentation rate (ESR) $(90 \mathrm{~mm} / \mathrm{hr})$ with a calcium level of $17.1 \mathrm{mg} / \mathrm{dL}$ (corrected for albumin of $2.47 \mathrm{mg} / \mathrm{dl}$ ), vitamin D3 level of $29.27 \mathrm{ng} / \mathrm{mL}$, phosphorus $7 \mathrm{mg} / \mathrm{dL}$, and alkaline phosphatase of $187 \mathrm{IU} / \mathrm{L}$. Her creatinine level was $1.66 \mathrm{mg} / \mathrm{dL}$. The estimated glomerular filtration rate (GFR) (calculated through the Cockcroft-Gault equation) was $40 \mathrm{~mL} / \mathrm{min}$. Serum parathyroid hormone (PTH) was $3.60 \mathrm{pg} / \mathrm{mL}$, with corresponding corrected calcium of $17.1 \mathrm{mg} / \mathrm{dl}$. She was treated with intravenous (IV) fluid hydration, loop diuretics, and renal corrected dose of zoledronic acid while the etiology of hypercalcemia was being sought. Workup for multiple myeloma and tuberculosis was negative. Considering sarcoidosis and lymphoma as differentials, ensuing workup revealed high serum angiotensin-converting enzyme (ACE) and 1,25 dihydroxyvitamin D levels (-Table 1). Chest X-ray was unremarkable. Fluorodeoxyglucose positron emission tomography (FDG PET) scan revealed hepatosplenomegaly with multiple hypermetabolic cervical, mediastinal axillary, and inguinal lymph nodes. Inguinal lymph node biopsy was done for confirmation. Histopathological evaluation of the inguinal lymph node was suggestive of noncaseating granulomatous lymphadenitis, confirming the diagnosis of sarcoidosis. Following the diagnosis of sarcoidosis, she was started on oral prednisone at $0.5 \mathrm{mg} / \mathrm{kg}$, which led to a gradual fall and normalization in calcium levels and improvement in renal functions over 2 months

\section{Discussion}

Sarcoidosis is complicated by disordered vitamin D and calcium metabolism, which has important implications with regard to disease activity and bone health. It is essential that we optimize the levels of vitamin D in patients with sarcoidosis due to the following reasons: First, vitamin D is an essential immunomodulator that may have a positive
Table 1 Biochemical parameters at presentation

\begin{tabular}{|c|c|}
\hline Hemoglobin (mg/dL) & 11.3 \\
\hline WBC count (cells $/ \mathrm{mm}^{3}$ ) & 8000 \\
\hline Platelet count (cells $/ \mathrm{mm}^{3}$ ) & 468000 \\
\hline ESR (mm 1st hr) & 90 \\
\hline Total protein $(\mathrm{g} / \mathrm{dL})$ & 8.1 \\
\hline Albumin $(\mathrm{g} / \mathrm{dL})$ & 2.47 \\
\hline Calcium (mg/dL) & 14.1 \\
\hline Phosphorous (mg/dL) & 7 \\
\hline Alkaline phosphatase (IU/L) & 187 \\
\hline Creatinine (mg/dL) & 1.66 \\
\hline Vitamin D (ng/mL) & 29.27 \\
\hline $\begin{array}{l}\text { PTH }(\mathrm{pg} / \mathrm{mL}) \\
\text { (normal range:15-68.3) }\end{array}$ & 3.60 \\
\hline $\begin{array}{l}\text { 1,25-dihydroxyvitamin } \mathrm{D}(\mathrm{pg} / \mathrm{mL} \text { ) } \\
\text { (normal range:19.9-79.3) }\end{array}$ & $>200$ \\
\hline $\begin{array}{l}\text { Serum ACE }(U / L) \\
\text { (normal range:12-68) }\end{array}$ & 140 \\
\hline
\end{tabular}

Abbreviations: ACE, angiotensin-converting enzyme; ESR, erythrocyte sedimentation rate; PTH., parathyroid hormone; WBC, white blood cell.

effect in patients with sarcoidosis. ${ }^{7}$ Kamphuis et al noted that disease activity of sarcoidosis measured by somatostatin receptor scintigraphy (SRS) correlated negatively with serum levels of 25-(OH)D. Thus, a low serum level of 25-(OH)D could be a possible risk factor for disease activity in sarcoidosis. ${ }^{4}$ Second, untreated patients with sarcoidosis have low bone mineral density (BMD) compared to age-matched controls. ${ }^{8}$ Third and most importantly, bone health in patients with sarcoidosis is further affected by the longterm use of corticosteroids in treating the active disease. ${ }^{9}$

On the other hand, several studies have shown that administering vitamin $\mathrm{D}$ to patients with sarcoidosis increases the risk of hypercalcemia. Overton et al reported hypercalcemia in $11 / 120(9.2 \%)$ patients after high-dose vitamin D (50,000 IU per week for 8 weeks) supplementation. Of these, $81.8 \%$ had baseline hypercalcemia and $36.4 \%$ had elevated baseline calcitriol. The authors suggested that vitamin D supplementation can be considered in those with normal baseline calcium, but it should be given with caution in those with elevated baseline calcium. ${ }^{10}$ Sodhi et al noted hypercalcemia more frequently in the sarcoid group that received pharmacological doses of vitamin $\mathrm{D}(42.3 \%)$ as compared to the nonsupplemented group (18.3\%). Patients who received a vitamin $\mathrm{D}$ prescription developed moderate and severe hypercalcemia more frequently (12.8\%) as compared to the group that did not receive vitamin $\mathrm{D}(3.6 \%){ }^{11}$ Our patient developed severe hypercalcemia after pharmacological doses of vitamin D supplementation. Unfortunately, baseline calcium and vitamin D levels before supplementation were not available. We speculate that baseline calcium levels might have been high, leading to severe hypercalcemia with supplementation. 
The optimal dose and treatment targets for vitamin D deficiency in sarcoidosis patients are not known. There is a need for randomized clinical trials to determine the safety of vitamin $\mathrm{D}$ dosing, as suggested by guidelines for the general population, in the sarcoidosis group. ${ }^{12}$ However, from the available data, most patients with sarcoidosis appear to tolerate smaller doses of vitamin D (200 to 400 IU daily) without manifesting hypercalcemia. ${ }^{4,13,14}$ As for the vitamin $\mathrm{D}$ targets in sarcoidosis, Saidenberg-Kernamac'h et al observed that serum 25-hydroxyvitamin D between 10 and $20 \mathrm{ng} / \mathrm{mL}$ was significantly associated with higher BMD in patients with sarcoidosis. Conversely, values greater than $20 \mathrm{ng} / \mathrm{mL}$ were associated with increased risk of fracture, probably related to increased bone resorption by increased formation of 1,25 dihydroxy vitamin $D$. The authors suggested that in sarcoidosis patients, known to be more sensitive to vitamin $\mathrm{D}$, the optimal range of 25 hydroxyvitamin $\mathrm{D}$ levels might be lower than that desirable for the general population. $^{15}$

\section{Conclusion}

This case highlights the importance of practicing caution when prescribing vitamin $\mathrm{D}$, particularly in patients with a background of granulomatous diseases. Cautious replacement of vitamin $\mathrm{D}$ in smaller doses, aiming for a lower target of vitamin D approaching $20 \mathrm{ng} / \mathrm{dl}$, may be a reasonable approach to the treatment of vitamin D deficiency in normocalcemic patients with sarcoidosis. A further prospective interventional investigation involving larger cohorts of patients is warranted to determine an optimal treatment regimen.

\section{Note}

Informed consent was obtained from all individual participants included in the study. All procedures performed in the study involving human participants were in accordance with the 1964 Helsinki Declaration and its later amendments or comparable ethical standards.

Conflict of Interest

None declared.

\section{References}

1 Kamboj P, Dwivedi S, Toteja GS. Prevalence of hypovitaminosis D in India \& way forward. Indian J Med Res 2018;148(05):548-556

2 Sarathi V, Karethimmaiah H, Goel A. High-dose vitamin D supplementation precipitating hypercalcemic crisis in granulomatous disorders. Indian J Endocrinol Metab 2017;21(06):815-819

3 Iannuzzi MC, Rybicki BA, Teirstein AS. Sarcoidosis. N Engl J Med 2007;357(21):2153-2165

4 Kamphuis LS, Bonte-Mineur F, van Laar JA, van Hagen PM, van Daele PL. Calcium and vitamin D in sarcoidosis: is supplementation safe? J Bone Miner Res 2014;29(11):2498-2503

5 Baughman RP, Lower EE. Sarcoidosis. In: Jameson JL, Kasper DL, Longo DL, Fauci AS, Hauser SL, Loscalzo J, eds. Harrison's Principles of Internal Medicine. New York: McGraw Hill Education; 2018

6 Chandrashekariah S, Rosha D. Sarcoidosis in India: investigation into vitamin D and calcium metabolism. Eur Respir J 2014;44 (Suppl 58):3777

7 Richmond BW, Drake WP, Vitamin D. Vitamin D, innate immunity, and sarcoidosis granulomatous inflammation: insights from mycobacterial research. Curr Opin Pulm Med 2010;16(05):461-464

8 Rúa-Figueroa I, Gantes MA, Erausquin C, Mhaidli H, Montesdeoca A. Vertebral sarcoidosis: clinical and imaging findings. Semin Arthritis Rheum 2002;31(05):346-352

9 Grossman JM, Gordon R, Ranganath VK, et al. American College of Rheumatology 2010 recommendations for the prevention and treatment of glucocorticoid-induced osteoporosis. Arthritis Care Res (Hoboken) 2010;62(11):1515-1526

10 Overton C, Le T, Iden T, Syed A, Kashiouris M, Syed H. Effect of vitamin D supplementation on calcium levels in patients with sarcoidosis: a retrospective analysis. Arthritis Rheumatol 2019; 71(Suppl 10):

11 Sodhi A, Aldrich T. Vitamin D supplementation: not so simple in sarcoidosis. Am J Med Sci 2016;352(03):252-257

12 Holick MF, Binkley NC, Bischoff-Ferrari HA, et al; Endocrine Society. Evaluation, treatment, and prevention of vitamin D deficiency: an Endocrine Society clinical practice guideline. J Clin Endocrinol Metab 2011;96(07):1911-1930

13 Burke RR, Rybicki BA, Rao DS. Calcium and vitamin D in sarcoidosis: how to assess and manage. Semin Respir Crit Care Med 2010; 31(04):474-484

14 Bolland MJ, Wilsher ML, Grey A, et al. Randomised controlled trial of vitamin D supplementation in sarcoidosis. BMJ Open 2013;3 (10):e003562

15 Saidenberg-Kermanac'h N, Semerano L, Nunes H, et al. Bone fragility in sarcoidosis and relationships with calcium metabolism disorders: a cross sectional study on 142 patients. Arthritis Res Ther 2014;16(02):R78 